\title{
EDITORIALS
}

\section{Human to human transmission of H7N9}

\author{
Limited transmission between humans is not surprising
}

\author{
James W Rudge lecturer ${ }^{1}$, Richard Coker professor $^{12}$ \\ ${ }^{1}$ Communicable Diseases Policy Research Group, London School of Hygiene and Tropical Medicine, Mahidol University, Bangkok 10400, Thailand; \\ ${ }^{2}$ Saw Swee Hock School of Public Health, National University of Singapore, Singapore
}

Since the new avian influenza virus, H7N9, first emerged in China, a primary concern has been whether it might spread between humans. The vast majority of the 133 confirmed cases reported so far seem to be epidemiologically unconnected, with many patients reporting a recent history of exposure to live poultry, which are suspected to be a main reservoir for the virus. Although an earlier study did report two family clusters of H7N9 cases, it was unclear whether these clusters resulted from person to person transmission or simply from exposure to a common animal source of infection. ${ }^{1}$

In the linked paper (doi:10.1136/bmj.f4752) by Qi and colleagues, a detailed investigation into one of these clusters provides the strongest evidence yet of $\mathrm{H} 7 \mathrm{~N} 9$ transmission between humans. ${ }^{2}$ The index case, a 60 year old man, was likely to have been infected at a nearby live poultry market, and subsequently developed a severe and ultimately fatal respiratory illness. His 32 year old daughter, who provided prolonged bedside care for her father before his admission to intensive care, later also became fatally infected. With no indication that the daughter was exposed to live poultry within the days before becoming sick, along with almost $100 \%$ genetic similarity between the viruses isolated from each patient, the evidence points to transmission from father to daughter.

As the authors acknowledge, there are some limitations to the study but, on balance, human to human transmission looks probable. So does this imply that H7N9 has come one step closer towards adapting fully to humans? Probably not. Crucially, there is still no evidence of sustained transmission among humans-all 43 close contacts of these two patients, including a son in law who also helped care for the father, tested negative for infection. In addition, the receptor binding sites of the viruses from the two patients are no more adapted towards humans than those of other available H7N9 isolates. In many ways, the evidence corroborates, rather than challenges, previous assertions that the transmissibility of H7N9 between humans is currently low.

Indeed, the occasional transmission event from human to human appears to be the norm rather than the exception for influenza viruses that sporadically cross the species barrier into humans.
Limited human to human transmission has been reported for highly pathogenic avian influenza $\mathrm{H} 5 \mathrm{~N} 1,{ }^{3}{ }^{4}$ which continues to cause (usually fatal) infections in humans, as well as another bird flu subtype, H7N7, which caused an outbreak of mostly mild infections in the Netherlands in $2003 .{ }^{5}$ To observe some transmission of H7N9 from human to human is therefore not surprising, and does not necessarily indicate that the virus is on course to develop sustained transmission among humans.

Nevertheless, several traits of H7N9 are of particular concern. The linked paper ${ }^{2}$ comes close on the heels of studies showing airborne transmissibility of H7N9 between ferrets in the laboratory, a mammalian model. ${ }^{67}$ Also, it is now well documented that owing to its non-lethality in birds, H7N9 can spread undetected through avian populations. In addition, Chinese surveillance data suggest that the number of confirmed human cases is just the tip of the iceberg-many mild cases are likely to have passed undetected. ${ }^{8}$ The upside of this is that the actual fatality rate among H7N9 cases is likely to be substantially lower than that observed among confirmed cases. ${ }^{9}$ The flipside is that the incidence of human infections, and therefore opportunities for H7N9 to adapt to humans or to re-assort through mixed influenza infections, could be much greater than for other bird flu viruses such as H5N1.

Although the number of H7N9 cases has fallen abruptly since April 2013, with no new cases reported for several weeks, we have been warned to expect a resurgence later in the year owing to seasonal effects on transmission. ${ }^{10}$ Thus, while the paper by Qi and colleagues ${ }^{2}$ might not suggest that H7N9 is any closer to delivering the next pandemic, it does provide a timely reminder of the need to remain extremely vigilant: the threat posed by H7N9 has by no means passed.

Competing interests: We have read and understood the BMJ Group policy on declaration of interests and declare that $\mathrm{RC}$ has received funding via research grants from Roche to the London School of Hygiene and Tropical Medicine of $\$ 1.8 \mathrm{~m}$ over five years, to conduct surveillance on flu in Indonesia (on which JWR has also been involved), and $\$ 1 \mathrm{~m}$ over four years to support a clinical registry of human cases of $\mathrm{H} 5 \mathrm{~N} 1$ in South East Asia. No other conflicts of interest are declared. 
Provenance and peer review: Commissioned; not externally peer reviewed.

1 Li Q, Zhou L, Zhou M, Chen Z, Li F, Wu H, et al. Preliminary report: epidemiology of the avian influenza A (H7N9) outbreak in China. N Engl J Med 2013, doi:10.1056/ avian influenza $A$ (

2 Qi X, Qian Y-H, Bao C-J, Guo X-L, Cui L-B, Tang F-Y, et al. Probable person to person transmission of novel avian influenza A (H7N9) virus in Eastern China, 2013: epidemiological investigation. BMJ 2013;347:f4752.

3 Wang H, Feng Z, Shu Y, Yu H, Zhou L, Zu R, et al. Probable limited person-to-person transmission of highly pathogenic avian influenza A (H5N1) virus in China. Lancet 2008;371:1427-34.

4 Ungchusak K, Auewarakul P, Dowell SF, Kitphati R, Auwanit W, Puthavathana P, et al. Probable person-to-person transmission of avian influenza A (H5N1). N Engl J Med 2005;352:333-40.

5 Du Ry van Beest Holle M, Meijer A, Koopmans M, de Jager CM. Human-to-human transmission of avian influenza A/H7N7, The Netherlands, 2003. Euro Surveill 2005;10:264-8.
6 Zhang Q, Shi J, Deng G, Guo J, Zeng X, He X, et al. H7N9 influenza viruses are transmissible in ferrets by respiratory droplet. Science 2013, doi:10.1126/science.1240532. Belser JA, Gustin KM, Pearce MB, Maines TR, Zeng H, Pappas C, et al. Pathogenesis and transmission of avian influenza A (H7N9) virus in ferrets and mice. Nature 2013, doi:10.1038/nature12391.

8 Ip DK, Liao Q, Wu P, Gao Z, Cao B, Feng L, et al. Detection of mild to moderate influenza A/H7N9 infection by China's national sentinel surveillance system for influenza-like illness: case series. BMJ 2013;346: $\{3693$.

9 Yu H, Cowling BJ, Feng L, Lau EH, Liao Q, Tsang TK, et al. Human infection with avian Yu H, Cowling BJ, Feng L, Lau EH, Liao Q, Tsang TK, et al. Human infection with avian
influenza A H7N9 virus: an assessment of clinical severity. Lancet 2013;382:138-45.

10 Centers for Disease Control and Prevention. Avian influenza A (H7N9) virus. 2013. www. cdc.gov/flu/avianflu/h7n9-virus.htm.

Cite this as: BMJ 2013;347:f4730

(c) BMJ Publishing Group Ltd 2013 